\title{
Ueber den Cysticercus taeniae gracilis, eine freie Cestodenamme des Barsches.
}

\author{
Von
}

\author{
Dr. von Linstow
}

in Ratzeburg.

Hierzu Fig. 1-5, Taf. XXI.

Bei den grossen Fortschritten, die in den letzten Jahren in der Erforschung der Entwicklungsgeschichte der Tänien gemacht sind, muss es auffallen, dass die Vogeltänien denen der Säugethiere gegenüber in der hierauf bezüglichen Literatur eine so überaus dürftige Rolle spielen. Unsere Kenntniss ist auf zwei Species beschränkt, den vielbesprochenen Cysticercus limacis ${ }^{1}$ ) oder arionis aus Arion ater, welcher in Totanus hypoleucos zur Taenia arionis von Sieb. erwächst, und Gryporrhynchus pusillus $\cdot N o r d m .{ }^{2}$ ) aus Tinca chrysitis, der in Ardea nycticorax als Taenia macropeos Wedl. geschlechtsreif wird. Seit längerer Zeit besitze ich nun einen dritten Cysticercus und die dazu gehörige Tänie, ohne bisher im Stande gewesen zu sein, aus den höchst mangelhaften Beschreibungen Diesing's die Art bestimmen zu können, was mir erst durch das schöne Werk $\mathrm{Kr}$ abbe's möglich wurde.

Beim Untersuchen eines Barsches fand ich in dem Magen desselben ein zweites von ersterem verschlungenes kleines Exemplar,

1) Leuckart: Die menschlichen Parasiten, Bd. I, Fig. 51.

2) Nordmann: Mikrograph. Beitr. 1, 101, Tab. VחI, 6 . 
und in dessen Darminhalt entdeckte ich bei der mikroskopischen Prüfung desselben neben einer Anzahl kleiner Crustaceen den näher zu beschreibenden Cysticercus, der seiner Kleinheit wegen sehr schwer zu isoliren war, da er mit blossem Auge kaum sichtbar ist. Das Gebilde, frei im Darminhalt liegend, ist 0,14 Mm. lang und 0,09 Mm. breit; im Centrum befinden sich 8 Haken von etwa $0,08 \mathrm{Mm}$. Länge und genau der Gestalt, wie sie Taenia gracilis Krabbe (Zeder) zeigt. Der Cysticercus bat eine doppelte Hüllmembran, yon denen die äussere homogen, die innere fein punktirt ist; die Pünktchen entsprechen wahrscheinlich den optischen Durchschnitten von Muskelfasern, die man auf der Fläche als parallele Querstreifung sieht; auch Längsstreifen zeigen sich; nach der oberen Seite zu, wohin die Wurzelenden der Haken gerichtet sind, findet sich eine trichterförmige Einbuchtung der Hüllen, während dieselben am entgegengesetzten Pole verdickt sind. In der Verlängerung der Spitzen der Haken zeigt sich ein schlauchförmiger, mehrfach eingeschnürter Körper, der offenbar die erste Anlage der Tänienproglottiden darstellt. Ausserdem bemerkt man kleine runde, mitunter doppeltconturirte Körperchen, von denen ich nicht weiss, ob sie dem Inhalt oder den Hüllen des Cysticercus angehören. Es ist nun wohl erlaubt, als hierzu gehörige Tänie die Taenia gracilis Krabbe zu bezeichnen, wegen der völligen Uebereinstimmung der betreffenden Haken in Zahl, Form und Grösse. Fütterungsversuche werden sich wo hl nur in der Weise anstellen lassen, dass man junge Barsche die reifen Proglottiden dieser Tänie fressen lässt, was mir bisher unmöglich war, da ich die letztere erst einmal und zwar nicht, wie zu vermuthen, in Anas boschas dom. et fera oder Anas Penelope, sondern in Mergus merganser gefunden habe, der allerdings auch gelegentlich von jungen Barschen lebt. Meine Exemplare waren 10-15 Mm. lang, die Haken des Skolex stimmen genau mit denen, wie Krabbe sie abbildet und beschreibt ${ }^{1}$ ). Den Text Krabbe's will ich, da das Dänische nicht jedem Leser geläufig sein dürfte, mir erlauben, herzusetzen. „Bloch (Nr. 4, S. 14 und Tab. III, Fig. 3-4) beschreibt unter dem Namen T. collo longissimo Bandwürmer bei Anas boschas und Penelope, von welchen er bemerkt, dass der Kopf sehr leicht abgeht und deshalb schwierig zu bekommen ist. Die Kennzeichen sind übrigens sehr mangelhaft angegeben.

1) Krabbe: Bidrag til Kundskab om Fuglenes Baendelorme, pag. 51, Tab. VII, Fig. 154-155. 
Zeder (Nr. 16, S. 347) nannte diesen Wurm T. gracilis. Da es kaum klar gestellt werden kann, welche Art Bloch vor sich gehabt hat, darf es mir erlaubt sein, Z e ders Benennung für diesen Wurm anzunehmen, von welchem ich schon verschiedene Male einige Exemplare bei Enten gefunden habe (August 1865, October und November 1868), und von welchen die Köpfe immer im Darmschleim, getrennt von den Gliedern, gefunden wurden. Der Schnabel war mit 8 Haken versehen (Fig. 154), von $0,077-0,080 \mathrm{Mm}$. Länge (Fig. 155). Die Geschlechtsöffnungen sind einseitig und die Geschlechtstheile gleichen denen von T. sinuosa. Eier fanden sich nicht."

Hierzu muss ich bemerken, dass ich den Skolex häufig noch in Verbindung mit dem übrigen Wurm gefunden habe, dass aber die Genitalien der Zeichnung, wie sie Krabbe von T. sinuosa (l. c. Tab. VIII, Fig. 153) gibt, durchaus nicht gleichen, weshalb ich eine Zeichnung des Randes zweier Proglottiden mit den Cirren beifüge.

\section{Erklärung der Abbildungen.}

Fig. 1. Vergr. 350. Freier Cysticercus Taeniae gracilis aus Perca fluviatilis. Fig. 2. Vergr. 500. Einzelner Haken.

Fig. 3. Natürliche Grösse. Taenia gracilis Krabbe aus Mergus merganser. Fig. 4. Vergr. 150. Rand zweier Proglottiden mit Cirren.

Fig. 5. Vergr. 90. Skolex der Tänie. 

